\title{
Polymerase chain reaction ribotyping of Clostridium difficile isolates in Qatar: a hospital-based study
}

\author{
Asma A Al-Thani ${ }^{1 *}$, Wedad S Hamdi ${ }^{1}$, Naser A Al-Ansari ${ }^{2}$ and Sanjay H Doiphode ${ }^{2}$
}

\begin{abstract}
Background: Clostridium difficile infection (CDI) is not generally reported to public health authorities in the Middle East and its true prevalence remains largely unknown. The aims of this study were to determine the prevalence of CDI and its associated ribotypes among C. difficile isolates in Qatar. Influence of age and correlation with other risk factors e.g. proton pump inhibitor use, antibiotic use, existence of chronic conditions, etc was also investigated for CDI positive patients.

Methods: A total of 1,532 patients with suspected CDI were recruited from two hospitals between 2011 and 2012. C. difficile was identified using glutamate dehydrogenase $(\mathrm{GDH})$ lateral flow assay and toxins $A$ and $B$ Enzyme Immunoassay (EIA). The C. difficile positive samples were then cultured for PCR-ribotyping.

Results: 122 of the 1,532 (7.9\%) samples from individual patients were identified as C.difficile positive; and 79 of these were viably cultured ( 65\%). From these, 36 different PCR ribotypes were isolated, of which strains 258 (6 [7.6\%]), 01/014/046 (5 [6.3\%]), and 011/053/056/107 (4 [5\%]) were the most prevalent. The prevalence of PCR-ribotype 027 was $1.3 \%(n=1)$. An age of $\geq 65$ years and treatment with proton pump inhibitors correlated with higher frequency of CDI. Treatment with third generation cephalosporins (50 [41\%]) and piperacillin/tazobactam antibiotics (55 [45.1\%]) was most frequently associated with CDI.

Conclusion: The most common C. difficile ribotype identified in Qatar was 258, which is different from those found in North America, Europe and Asia. The prevalence of CDI was higher in Qatar than Europe; though comparable to other Middle Eastern countries. These findings underscore the importance of local surveillance to detect and control $\mathrm{C}$. difficile infection.
\end{abstract}

Keywords: Clostridium difficile, Ribotype, Qatar

\section{Background}

Infection with Clostridium difficile is a common cause of diarrhoea, especially diarrhoea associated with a history of antibiotic use [1]. C. difficile has been identified as the major pathogen implicated in nosocomial diarrhoea arising $>72$ hours after admission among patients receiving antibiotics [2]. The infection can range from mild diarrhoea to severe pseudomembranous colitis. Risk factors for $C$. difficile infection (CDI) include antibiotic exposure, hospitalisation, and advanced age [1].

The epidemiology and microbiology of CDI varies according to regional differences. In North America and Europe, the epidemiology of CDI is well-documented.

\footnotetext{
*Correspondence: aaja@qu.edu.qa

${ }^{1}$ Virology Health Sciences Department, College of Arts and Sciences, Qatar University, Doha, Qatar

Full list of author information is available at the end of the article
}

For example, the clindamycin-resistant ribotype 017 strain of apparent clonal origin has been the cause of epidemics in Canada, the Netherlands, Ireland and Asia [3-7]. However, ribotypes 027 and 078, which are the main causes of outbreaks in other regions of the world, appear to be rare in Asian countries [7]. It is important to assess CDI in the Arab world, where limited data are available on both CDI prevalence and its ribotypes, despite over-prescription of antibiotics in this region [8-12].

In Qatar, CDI is not necessarily reported to the public health authorities and its true prevalence remains unknown. This may be due to the poor awareness of antibiotic resistance and its association with CDI among physicians, thus highlighting the need for increased awareness and surveillance of CDI in Qatar and characterizing the circulating strains.

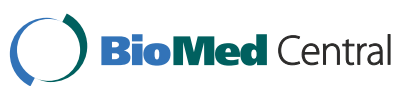


The aim of the present study is to investigate the epidemiology of CDI in patients admitted to Hamad General Hospital and Al-Khor Hospital in Qatar and identify the specific ribotypes associated with CDI in Qatar. In addition, the influence of age and correlation with other factors such as proton pump inhibitor use, antibiotic use, existence of chronic conditions, etc was also investigated.

\section{Methods}

\section{Patients}

From October 2011 to August 2012, consecutive patients with suspected CDI admitted to Hamad General Hospital and Al-Khor Hospital, Qatar, were included in the study. Both of these hospitals are part of the Hamad Medical Corporation, an academic institute, which comprises seven hospitals and a total of 2,070 beds. Hamad General Hospital is a 603-bed hospital, serving the population of Doha city. Its services include trauma \& emergency medicine, paediatrics, critical care, specialised surgery, specialised medicine, laboratory medicine and radiology services, The hospital treats between 1,200 and 1,500 patients on average per day. Al-Khor Hospital is a 149-bed community hospital serving Northern Qatar. The hospital services include emergency medicine, general surgery, orthopedics, ENT, urology, dentistry, endocrine medicine, gastroenterology, dialysis, psychiatry, paediatric medicine, obstetrics and gynecology and general intensive care.

Recruited patients included those that were admitted to the hospital with diarrhoea and those who developed diarrhoea during hospitalisation. The inclusion criteria were: presence of diarrhoea (watery, loose or unformed stool passed at a frequency of three times or more within 24 hours); recent (within the last 3 months) antibiotic exposure (as recent antibiotics exposure has been linked to increased risk of CDI); abdominal pain; fever; and a distinctive foul stool odour. Exclusion criteria included: Children $\leq 12$ months of age, no recent (within 3 months) antibiotic exposure; gastrointestinal symptoms without diarrhoea. Patients were not included in the study more than once if they had recurrent symptoms.

Hospital acquired diarrhoea was defined as diarrhoea which developed $\geq 48$ hours after admission. Communityacquired diarrhoea was defined as diarrhoea, which developed before 48 hours of admission. CDI was defined as diarrhoea in a patient with a stool culture positive for $C$. difficile.

The Research Ethical Committee of Hamad Medical Corporation, Qatar approved the study. Informed consent was obtained from all participants (or parents in case of children under 16 yr of age).

For the patients identified as CDI positive, risk factor analysis for association with specific ribotypes was carried out. Factors investigated for correlation with CDI included; proton pump inhibitors (PPI) use; older age; medicinal steroid use; non-steroidal anti-inflammatory drug (NSAID) use; immunosuppression; chemotherapy; chronic kidney disease (CKD);chronic liver disease (CLD); organ transplant; or inflammatory bowel disease (IBD) . These factors were primarily identified through patient's medical history.

\section{Assessment \& isolation of C. difficile}

The stool samples were sent to the Hamad General Hospital Laboratory within a few hours of onset of diarrhoea.

The samples were tested for C.difficile using Glutamate Dehydrogenase (GDH) lateral flow assay (Clostridium difficile Quik Chek Complete, Techlab, Alere North America LLC), toxins $\mathrm{A}$ and $\mathrm{B}$ by Enzyme Immunoassay (EIA) and PCR as per the manufacturer's instructions (GeneXpert, Cepheid, CA, USA).

GDH assay, toxins A and B EIA were first-line screening tests. All samples were then tested using PCR. If the PCR did not show consistent results with the initial screening tests during the first attempt, it was repeated using new reagents and a new cartridge. If the results were negative upon re-testing, the specimen was not considered C.difficile positive. Isolates that were shown to be $C$. difficile negative during the initial screen were not characterised further.

\section{DNA Extraction}

C. difficile DNA was extracted from blood agar subcultured colonies, using a Chelex resin-based DNA extraction kit (InstaGene Matrix; Bio-Rad, USA).

\section{PCR Ribotyping}

The C.difficile positive samples identified were cultured in C.difficile selective media (Cycloserine Cefoxitin Fructose Agar, CCFA) (bioMérieux, St. Louis, MO) after ethanol shock.

Each specimen $(1 \mathrm{ml})$ was homogenized in $1 \mathrm{ml}$ of absolute alcohol, vortexed to form an even suspension, and left to stand at room temperature for up to $1 \mathrm{hr}$. A 50-75 $\mu \mathrm{l}$ aliquot of this deposit was inoculated onto each of the Cycloserine _cefoxitin fructose plate agar to obtain isolated bacterial colonies. All media were incubated at $37^{\circ} \mathrm{C}$ in an anaerobic workstation. The cultures were incubated for 48 to $72 \mathrm{~h}$. Tests carried out to positively identify $\mathrm{C}$. difficile were the following; morphology, odour (Horse manure odour), fluorescence and latex (when necessary).

PCR-ribotyping was performed on the cultured pure colonies of $C$. difficile using the ribotyping protocol provided by Cambridge University, HPA Microbiology Services, Clinical Microbiology Laboratory, UK.

Briefly, amplification reactions were performed as per Leeds Laboratory Protocol [13], in $45 \mu \mathrm{l}$ PCR tubes, 
containing $34.5 \mu \mathrm{l}$ RNase/DNase free water; $5.0 \mu \mathrm{l}$ of 10× RT-PCR reaction Mix; $2.25 \mu \mathrm{l} \mathrm{mM} \mathrm{MgCl}_{2} ; 2 \mu \mathrm{l}$ of $10 \mathrm{mM} \mathrm{dNTP;} 0.5 \mu \mathrm{l}$ of $50 \mathrm{pmol} / \mathrm{ul}$, forward and reverse primers for the intergenic 16S-23S rRNA Spacer Regions of $C$. difficile (Forward 5'- 6 FAM - GTG CGG CTG GAT CAC CTC CT- 3' and reverse 5'- CCC TGC ACC CTT AAT AAC TTG ACC- 3'); $0.25 \mu$ l Taq polymerase; and $5 \mu \mathrm{l}$ of extracted DNA template (or sterile water as a negative control). Amplifications were carried out in a thermal cycler (Touchgene Gradient; Techne) for 1 cycle of $2 \mathrm{~min}$ at $95^{\circ} \mathrm{C}$ for denaturation, followed by 30 cycles $\left(1 \mathrm{~min}\right.$ at $95^{\circ} \mathrm{C}, 1 \mathrm{~min}$ at $55^{\circ} \mathrm{C}$ and $1.5 \mathrm{~min}$ at $\left.72^{\circ} \mathrm{C}\right)$ and a final extension 7 mins at $72^{\circ} \mathrm{C}$.

\section{Fragment analysis}

ABI-3130 (Applied Biosystem, USA) instrument with POP-gel was used for fragment analysis. Peak Scanner software v1.0 was used for data analysis. The peak sizes of all major peaks were compared with peaks from reference strains (34 reference strains from a library of the most commonly encountered ribotypes in the UK), allowing for deviations $\pm 2 \mathrm{bp}$. The strains with banding patterns that did not match with the reference strains from the UK were sent to the Leeds Reference Laboratory, UK for ribotyping.

\section{Correlation analysis}

Patient records were examined for factors potentially correlating with CDI (age; proton pump inhibitor (PPI) use; medicinal steroid use; NSAID use; immunosuppression; chemotherapy; chronic kidney disease; chronic liver disease; organ transplant; inflammatory bowel disease). Only records of CDI positive patients were examined. The correlation with ribotypes was investigated using Crosstab analysis.

\section{Results}

\section{Patients}

A total of 1,532 patients with suspected CDI were recruited. One hundred and twenty two stool samples, out of total 1,532 patients, were C. difficile positive and were selected for sample analysis (Table 1). Of the 122 CDI positive patients , $98(80.3 \%$ or $6.4 \%$ of 1,532$)$ had hospital acquired CDI and $14(11.5 \%$ or $0.9 \%$ of 1,532$)$ had community-acquired CDI. Medical records for the remaining $10(8.2 \%)$ were not available to categorise them into hospital or community-acquired CDI. Amongst the hospital acquired patients, 5.7\% $(n=87 / 1,532)$ were from Hamad General Hospital and 0.7\% ( $\mathrm{n}=11 / 1,532)$ from Al Khor Hospital. Each sample represented an individual patient. All 122 patients were residents of Qatar though their ethnic background details are not available.
Table 1 Baseline patient characteristics of 122 patients with CDI

\begin{tabular}{|c|c|c|}
\hline Variable & Category & $\begin{array}{l}\text { No. Of } \\
\text { subjects } \\
\text { n (\%) }\end{array}$ \\
\hline Total number of subjects & Qatari residents & 122 \\
\hline \multirow[t]{2}{*}{ Gender } & Males & 72 (59\%) \\
\hline & Females & $50(41 \%)$ \\
\hline \multirow[t]{5}{*}{ Age } & $1-14$ yrs & $23(18.9 \%)$ \\
\hline & $15-30$ yrs & $15(12.3 \%)$ \\
\hline & $31-50$ yrs & $21(17.2 \%)$ \\
\hline & $51-64$ yrs & $22(18 \%)$ \\
\hline & $\geq 65$ yrs & $41(33.6 \%)$ \\
\hline Hospital acquired CDI & & $98(80.3 \%)$ \\
\hline Community acquired CDI & & $14(11.5 \%)$ \\
\hline Medical Records not available & & $10(8.2 \%)$ \\
\hline \multirow{20}{*}{$\begin{array}{l}\text { Antibiotics used prior to CDI } \\
\text { (some patients were on }>1 \text { ): }\end{array}$} & Tazocin & $55(45.1 \%)$ \\
\hline & $\begin{array}{l}\text { Third generation } \\
\text { Cephalosporins }\end{array}$ & $50(41 \%)$ \\
\hline & Amoxicillin & $22(18 \%)$ \\
\hline & Meropenom & $20(16.4 \%)$ \\
\hline & Ciprofloxacin & $20(16.4 \%)$ \\
\hline & Vancomycin & $15(12.3 \%)$ \\
\hline & Co-trimoxazole & $10(8.2 \%)$ \\
\hline & Azithromycin & $9(9.8 \%)$ \\
\hline & Amikacin & $6(7.4 \%)$ \\
\hline & Teicoplanin & $4(3.3 \%)$ \\
\hline & Nitrofurantoin & $2(1.6 \%)$ \\
\hline & Doxycyclin & $2(1.6 \%)$ \\
\hline & Tigecyclin & $1(0.8 \%)$ \\
\hline & Linezolid & $1(0.8 \%)$ \\
\hline & Cloxacillin & $1(0.8 \%)$ \\
\hline & Colistin & $1(0.8 \%)$ \\
\hline & Moxifloxacin, & $1(0.8 \%)$ \\
\hline & Ampicillin & $1(0.8 \%)$ \\
\hline & Septrin & $1(0.8 \%)$ \\
\hline & Amygdalin & $1(0.8 \%)$ \\
\hline
\end{tabular}

\section{PCR ribotyping}

Pure colonies of $C$. difficile were obtained from only 79 out of 122 CDI positive patient samples. In total, 36 different PCR ribotypes (Table 2) were identified among C. difficile strains isolated from the 79 successfully cultured strains. Of the 36 C. difficile PCR ribotypes isolated, the most frequent ones were $258(n=6$ [7.6\%]), followed by $001 / 014 / 046(n=5[6.3 \%])$, and then $011 / 053 / 056 / 107$ $(n=4[5 \%])$, followed by other PCR ribotypes (51.9\%) detailed in Table 2. The prevalence of the PCR-ribotype 027 was only $1.3 \%(n=1)$. Hence, the PCR ribotypes 
Table 2 Frequency and percentages of $C$. difficile ribotypes isolated in Qatar from 2011 to $2012(n=79)$

\begin{tabular}{|c|c|}
\hline C. difficile ribotype & Frequency $\mathrm{N}(\%)$ \\
\hline 258 & $6(7.6 \%)$ \\
\hline 001 & $5(6.3 \%)$ \\
\hline 014 & $5(6.3 \%)$ \\
\hline 046 & $5(6.3 \%)$ \\
\hline 011 & $4(5.1 \%)$ \\
\hline 053 & $4(5.1 \%)$ \\
\hline 056 & $4(5.1 \%)$ \\
\hline 107 & $4(5.1 \%)$ \\
\hline 015 & $3(3.8 \%)$ \\
\hline 017 & $3(3.8 \%)$ \\
\hline 023 & $3(3.8 \%)$ \\
\hline 183 & $3(3.8 \%)$ \\
\hline 016 & $2(2.5 \%)$ \\
\hline 081 & $2(2.5 \%)$ \\
\hline 084 & $2(2.5 \%)$ \\
\hline 087 & $2(2.5 \%)$ \\
\hline 097 & $2(2.5 \%)$ \\
\hline 103 & $2(2.5 \%)$ \\
\hline 104 & $2(2.5 \%)$ \\
\hline 003 & $1(1.3 \%)$ \\
\hline 004 & $1(1.3 \%)$ \\
\hline 020 & $1(1.3 \%)$ \\
\hline 027 & $1(1.3 \%)$ \\
\hline 078 & $1(1.3 \%)$ \\
\hline 106 & $1(1.3 \%)$ \\
\hline 116 & $1(1.3 \%)$ \\
\hline 126 & $1(1.3 \%)$ \\
\hline 174 & $1(1.3 \%)$ \\
\hline 186 & $1(1.3 \%)$ \\
\hline 193 & $1(1.3 \%)$ \\
\hline 216 & $1(1.3 \%)$ \\
\hline 248 & $1(1.3 \%)$ \\
\hline 353 & $1(1.3 \%)$ \\
\hline 436 & $1(1.3 \%)$ \\
\hline 095 & $1(1.3 \%)$ \\
\hline
\end{tabular}

predominantly found in Qatar during the period of this study were 258 followed by 001/014/046. Only one ribotype was isolated from each $C$. difficile colony.

\section{Correlating factors with $\mathrm{CDI}$ \\ Age}

The frequency of CDI in the 122 patients by age groups is shown in Table 1. The frequency of ribotypes isolated, from highest to lowest, was: 19 (24\%) from the $\geq 65 \mathrm{yr}$ group; 12 (15\%) from the 1-14 yrs group; 12 (15\%) from 51-64 yr group; 10 (12.6\%) from the 15-30 yr group; and 9 (11.3\%) from the 31-50 yr group. Both the CDI infection rate and frequency of ribotypes isolated were highest in the elderly age group ( $\geq 65 \mathrm{yr}$ ) (Table 1 for CDI).

\section{Other correlates}

Table 3 summarises other factors investigated for correlation with CDI. Several factors were thought to correlate with CDI, especially use of PPI treatment. Indeed, PPI use was more common in patients with CDI than being $\geq 65 \mathrm{yr}$ of age. However, due to the small sample sizes, statistical tests couldn't be accurately performed on this data.

\section{Discussion}

Our study showed presence of CDI in 122 of the 1,532 patients (prevalence of $7.9 \%$ during the period 2011 to 2012; 6.4\% of which were hospital acquired). Amongst the hospital acquired patients, 5.7\% $(\mathrm{n}=87 / 1,532)$ were from Hamad General Hospital and 0.7\% $(n=11 / 1,532)$ from $\mathrm{Al}$ Khor Hospital. The reason for the large difference between the hospitals is probably due to the presence of more patient samples, in our study, from Hamad General Hospital vs. Al Khor Hospital. Of the 122 CDI positive patients $98(80.3 \%)$ had hospital acquired CDI and $14(11.8 \%)$ had community-acquired CDI. The prevalence data found in our study are comparable to data from other Middle-Eastern countries (prevalence range 4.613.7\%; average 8.6\%) [14-18]. Comparatively, in Europe C. difficile infections are responsible for only $3.6 \%$ of all hospital acquired infections [19]. The difference may be attributed to over-prescription of antibiotics in the Middle East. However, it must be noted that the sample sizes used in this study and in the cited Middle Eastern studies are quite small compared to the large surveillance data gathered by the European surveillance study [19]. The key finding is that CDI appears to be doubled in patients in hospitals in the Middle East compared with Europe, and may be under-diagnosed. The difference in CDI illustrates the importance of active surveillance of CDI in hospitals in the Middle East and a need for regulation of antibiotic prescription.

The PCR ribotypes predominant in Qatar during this period were 258 followed by 001/014/046. The most common ribotypes isolated from two other countries in the Middle East were: 002, 001, 126 and 140 from Kuwait [16]; and 078 from Iran [20], respectively. However, there is very little data on other specific riborypes in the Middle East; whereas ribotypes 017, 018, 014, 002 and 001 have been shown to be most prevalent in Asia [21-25].

A study carried out by Bauer and colleagues in 34 European countries identified PCR ribotypes 014/020, 001, and 078 as the most prevalent in Europe [26]. The 
Table 3 Factors investigated for correlation with CDI $(n=122)$

\begin{tabular}{|c|c|c|}
\hline Correlating factors & Infected with CDI N = 122 (\%) & Correlating ribotypes \\
\hline PPI use ${ }^{*}$ & $65(53.3 \%)$ & $014,258,046,053,017$ and 001 \\
\hline Age $\geq 65 \mathrm{yr}$ & $41(33.6 \%)$ & $107,001,103,011,116,126,015,017,183,186,003,046,053,056,078,081,084$ \\
\hline Medicinal steroid use ${ }^{* \dagger}$ & $29(23.7 \%)$ & $258,014,001,106,107,015,016,183,193,353,046,081,095$ \\
\hline NSAID ${ }^{\dagger}$ & $28(23 \%)$ & $107,258,011,103,014,174,183,193,020,353,004,046,056,081,084,087$ \\
\hline Immunosupression & $25(20.5 \%)$ & $014,015,046,258,001,106,116,016,017,183,186,193,353$ \\
\hline Chemotherapy* $^{*}$ & $18(14.7 \%)$ & $046,001,106,116,014,183,186,193,216,258,003,353$ \\
\hline CKD & $17(14 \%)$ & $011,116,126,014,017,174,046,078,084$ \\
\hline CLD & $5(4.1 \%)$ & $183,186,003$ \\
\hline Organ-transplant & $4(3.3 \%)$ & 011 \\
\hline $\mathrm{IBD}$ & $1(0.8 \%)$ & 015,056 \\
\hline
\end{tabular}

*PPI: Proton Pump Inhibitor; NSAID: Non-steroidal anti-inflammatory drug; IBD: Inflammatory bowel disease; CKD: Chronic kidney disease; CLD: Chronic liver disease. ${ }^{\dagger}$ All treatments were administered up to 3 months prior to acquiring CDI.

NS: Non-significant.

prevalence of PCR-ribotype 027 was only $5 \%$ in this study [26], although this ribotype had been previously associated with increasing outbreaks of CDI in hospitals in North America, Japan and Europe [27]. This ribotype was isolated from only one sample in the present study and was not isolated in either the Kuwaiti or Iranian studies mentioned earlier $[16,20]$. It is important to note here that we managed to culture only 79 samples successfully out of the 122 with CDI. This low number might have led to under-representation of PCR ribotypes that caused CDI in our patient population.

The antibiotics most frequently correlating with CDI in our study were third generation cephalosporins and piperacillin/tazobactam. Third generation cephalosporins, even when administered as short-term perioperative prophylaxis, have been significantly associated with $C$. difficile-related diseases $[28,29]$. Piperacillin/tazobactam has also been linked to development of CDI, though tazocin is generally associated with lower risk of $C$. difficile infections $[30,31]$. The correlation of CDI with piperacillin/tazobactam in our study may reflect the over-prescribing of antibiotics in Qatar. The use of certain antibiotics, especially fluoroquinolones, has been previously associated with infection by PCR-ribotype $027[27,32]$. In our study the ribotype most associated with third generation cephalosporins and piperacillin/tazobactam use was 258 in 6 patients $(n=2$ and $n=4$ for each antibiotic, respectively).

In our study, CDI was most often correlated with older age ( $\geq 65 \mathrm{yrs})$ and use of PPIs. However, it must be noted that the number of infections for which these correlations were based was small. Old age and PPIs have been previously reported to be risk factor for CDI [33-35]. Controlled prescribing of PPIs, especially in high risk individuals, may be important in control of CDIs. No ribotype correlated significantly with any risk factor investigated.
Unfortunately patient outcomes after confirmation of CDI were not investigated, which is a limitation of this study and needs to be addressed in future studies. Additional limitations include missing data for the $10 \mathrm{pa}$ tients, which could not be classified in hospital-acquired or community-acquired CDI. These patients comprise $8.2 \%$ of the CDI positive population and their inclusion would have been useful here. Furthermore, in this study, we had small sample sizes for each age group and hence correlation of CDI with age will probably have to be repeated with larger samples. Overall, Qatar population is $\sim 350,000$ people and, although a relatively homogenous population, recruiting for clinical studies is limited by the small population size. Finally, while ribotype 027 was only identified in one sample, further surveillance is required to determine whether this strain is indeed present in the country and to monitor for its prevalence in a larger sample set.

\section{Conclusion}

The commonest $C$. difficile ribotype identified in Qatar was different from those found in North America, Europe and Asia. In addition, the prevalence of CDI was higher in Qatar than Europe; though comparable to other Middle Eastern countries. Restrictions on the use of antibiotics and PPIs should be considered in the Middle East. Unrestricted prescribing of medicine is complicated further by a lack of epidemiology data and surveillance of CDI in Middle-Eastern countries. These findings underscore the importance of local surveillance to detect and control $C$. difficile infection. The findings also highlight a need to control PPI prescriptions, especially in the elderly population.

\section{Competing interests}

Qatar National Research Foundation (National Priority Research Program) and Qatar University provided financial support to carry out this study. No other competing financial interests exist for any of the authors. 


\section{Authors' contributions}

AA-T designed this study. WS performed data analysis and drafted the manuscript. NA-A provided assistance with data collection and manuscript revision. SD collected samples and clinical data, participated in the design of the study and performed the statistical analysis. All authors read and approved the final manuscript.

\section{Acknowledgements}

This work was supported by Qatar University research grant, which is gratefully acknowledged. We are grateful to Ms. Mooza Al-Khinji, Ms. Sara N. Al-Thani and Ms. Khlood N. Rabeeba for their technical assistance. The authors would like to acknowledge support of Dr Sabah Allawati, from Medcommz Ltd, UK in providing editorial support for this article.

\section{Author details}

${ }^{1}$ Virology Health Sciences Department, College of Arts and Sciences, Qatar University, Doha, Qatar. 'Department of Laboratory Medicine and Pathology, Al-Khor Hospital, Hamad Medical Corporation, Doha, Qatar.

Received: 5 June 2014 Accepted: 10 September 2014 Published: 15 September 2014

\section{References}

1. Bartlett JG, Gerding DN: Clinical recognition and diagnosis of Clostridium difficile infection. Clin Infect Dis 2008, 46(Suppl 1):S12-S18.

2. Choi HK, Kye Kim H, Lee SH, Lee SJ: Risk factors for recurrence of Clostridium difficile infection: effect of vancomycin-resistant enterococci colonization. J Korean Med Sci 2011, 26(7):859-864.

3. Al-Barrak A, Embil J, Dyck B, Olekson K, Nicoll D, Alfa M, Kabani A: An outbreak of toxin A negative, toxin $B$ positive Clostridium difficileassociated diarrhea in a Canadian tertiary-care hospital. Can Commun Dis Rep 1999, 25(7):65-69.

4. Kuijper E, Weerdt J, Kato H, Kato N, Dam A, Vorm E, Weel J, Rheenen C, Dankert J: Nosocomial outbreak of Clostridium difficile-associated diarrhoea due to a clindamycin-resistant enterotoxin A-negative strain. Eur J Clin Microbiol Infect Dis 2001, 20(8):528-534.

5. Drudy D, Harnedy N, Fanning S, Hannan M, Kyne L: Emergence and control of fluoroquinolone-resistant, toxin A-negative, toxin B-positive Clostridium difficile. Infect Control Hosp Epidemiol 2007, 28(8):932-940.

6. Sadeghifard N, Salari MH, Ghassemi MR, Eshraghi S, Amin Harati F: The incidence of nosocomial toxigenic Clostridium difficile associated diarrhea in Tehran tertiary medical centers. Acta Med Iran 2010, 48(5):320-325.

7. Collins DA, Hawkey PM, Riley TV: Epidemiology of Clostridium difficile infection in Asia. Antimicrob Resis Inf Cont 2013, 2:21.

8. Abasaeed AE, Vlcek J, Abuelkhair MA, Andrajati R, Elnour AA: A comparative study between prescribed and over-the-counter antibiotics. Saudi Med J 2013, 34(10):1048-1054.

9. Zolaly MA, Hanafi MI: Factors affecting antibiotics' prescription in general pediatric clinics. J Taibah Univ Med Sci 2011, 6(1):33-41.

10. Abasaeed A, Vlcek J, Abuelkhair M, Kubena A: Self-medication with antibiotics by the community of Abu Dhabi Emirate, United Arab Emirates. J Infect Dev Ctries 2009, 3(7):491-497.

11. Suleiman IS, Rubian SS: Antibiotics use with and without a prescription in healthcare students. Am J Pharmac Sci 2013, 1(5):96-99.

12. Dar-Odeh NS, Abu-Hammad OA, Khraisat AS, El Maaytah MA, Shehabi A: An analysis of therapeutic, adult antibiotic prescriptions issued by dental practitioners in Jordan. Chemotherapy 2008, 54(1):17-22.

13. Hastings M: Anaerobe Reference Unit Operating Procedure Manual ASOP 39: PCR Ribotyping of Clostridium difficile, NPHS Microbiology Cardiff, issue 1 , issue date 13/11/06; 2006.

14. Jalali M, Khorvash $K$, Warriner $K$, Scott J: Clostridium difficile infection in an Iranian hospital. BMC Res Notes 2012, 5:159.

15. Sadeghifard N, Salari MH, Ranjbar R, Ghafouryan S, Raftari M, Abdulamir AS, Fatimah $A B$, Kazemi B: The clinical and environmental spread and diversity of toxigenic Clostridium difficile diarrheic in the region of the Middle East. Rev Infection 2010, 1:180-187.

16. Jamal W, Rotimi VO, Brazier J, Duerden Bl: Analysis of prevalence, risk factors and molecular epidemiology of Clostridium difficile infection in Kuwait over a 3-year period. Anaerobe 2010, 16(6):560-565.
17. Nasereddin LM, Bakri FG, Shehabi AA: Clostridium difficile infections among Jordanian adult hospitalized patients. Am J Infection Control 2009, 37 (10):864-866.

18. Rotimi VO, Mokaddas EM, Jamal WY, Verghese TL, el-Din K, Junaid TA: Hospitalacquired Clostridium difficile infection amongst ICU and burn patients in Kuwait. Med Princ Pract 2002, 11(1):23-28.

19. European Centre for Disease Prevention and Control: Point prevalence survey. http://www.ecdc.europa.eu/en/healthtopics/Healthcare-associated_infections/ point-prevalence-survey/Pages/Point-prevalence-survey.aspx Last accessed May 2014.

20. Jalali M, Khorvash F, Warriner K, Weese JS: Clostridium difficile infection in an Iranian hospital. BMC Res Notes 2012, 5:159.

21. Sawabe E, Kato H, Osawa K, Chida T, Tojo N, Arakawa Y, Okamura NL: Molecular analysis of Clostridium difficile at a university teaching hospital in Japan: a shift in the predominant type over a five-year period. Eur $J$ Clin Microbiol Infect Dis 2007, 26(10):695-703.

22. Kim H, Lee Y, Moon HW, Lim CS, Lee K, Chong Y: Emergence of Clostridium difficile ribotype 027 in Korea. Korean J Lab Med 2011, 31(3):191-196.

23. Cheng VC, Yam WC, Lam OT, Tsang JL, Tse EY, Siu GK, Chan JF, Tse H, To KK, Tai JW, Ho PL, Yuen KY: Clostridium difficile isolates with increased sporulation: emergence of PCR ribotype 002 in Hong Kong. Eur J Clin Microbiol Infect Dis 2011, 30(11):1371-1381.

24. Lim PL, Ling ML, Lee HY, Koh TH, Tan AL, Kuijper EJ, Goh SS, Low BS, Ang LP, Harmanus C, Lin RT, Krishnan P, James L, Lee CE: Isolation of the first three cases of Clostridium difficile polymerase chain reaction ribotype 027 in Singapore. Singapore Med J 2011, 52(5):361-364.

25. Kato H, Ito Y, van den Berg RJ, Kuijper EJ, Arakawa Y: First isolation of Clostridium difficile 027 in Japan. Euro Surveill 2007, 12(1), E070111.3.

26. Bauer MP, Notermans DW, van Benthem BH, Brazier JS, Wilcox MH, Rupnik M, Monnet DL, van Dissel JT, Kuijper EJ: ECDIS Study Group. Lancet 2011, 377(9759):63-73.

27. Kuijper EJ, Coignard B, Brazier JS, Suetens C, Drudy D, Wiuff C, Pituch H, Reichert $P$, Schneider F, Widmer AF, Olsen KE, Allerberger F, Notermans DW, Barbut F, Delmée M, Wilcox M, Pearson A, Patel BC, Brown DJ, Frei R, Akerlund T, Poxton IR, Tüll P: Update of Clostridium difficile-associated disease due to PCR ribotype 027 in Europe. Euro Surveill 2007, 12(6):E1-E2.

28. de Lalla F, Privitera G, Ortisi G, Rizzardini G, Santoro D, Pagano A, Rinaldi E, Scarpellini P: Third generation cephalosporins as a risk factor for Clostridium difficile-associated disease: a four-year survey in a general hospital. J Antimicrob Chemother 1989, 23(4):623-631.

29. Owens RC Jr, Donskey CJ, Gaynes RP, Loo VG, Muto CA: Antimicrobialassociated risk factors for Clostridium difficile infection. Clin Infect Dis 2008, 46(Suppl 1):S19-S31.

30. Mendez MN, Gibbs L, Jacobs RA, McCulloch CE, Winston L, Guglielmo BJ: Impact of a piperacillin-tazobactam shortage on antimicrobial prescribing and the rate of vancomycin-resistant enterococci and Clostridium difficile infections. Pharmacotherapy 2006, 26(1):61-67.

31. Garneau JR, Valiquette L, Fortier LC: Prevention of Clostridium difficile spore formation by sub-inhibitory concentrations of tigecycline and piperacillin/tazobactam. BMC Infect Dis 2014, 14:29.

32. Kuijper EJ, Coignard B, Tüll P: Emergence of Clostridium difficile-associated disease in North America and Europe. Clin Microbiol Infect 2006, 12(Suppl. 6):2-18.

33. Henrich TJ, Krakower D, Bitton A, Yokoe DS: Clinical risk-factors for severe Clostridium difficile-associated disease. Emerg Infect Dis 2009, 15:415-422.

34. Sailhamer EA, Carson K, Chang Y, Zacharias N, Spaniolas K, Tabbara M, Alam HB, DeMoya MA, Velmahos GC: Fulminant Clostridium difficile colitis. patterns of care and predictors of mortality. Arch Surg 2009, 144:433-439.

35. U.S. Food and Drug Administration: FDA Drug Safety Communication: clostridium difficile-associated diarrhea can be associated with stomach acid drugs known as proton pump inhibitors (PPIs). http://www.fda.gov/ drugs/drugsafety/ucm290510.htm Last accessed May 2014.

doi:10.1186/1471-2334-14-502

Cite this article as: Al-Thani et al:: Polymerase chain reaction ribotyping of Clostridium difficile isolates in Qatar: a hospital-based study. BMC Infectious Diseases 2014 14:502. 